\title{
Intelligent Multi-coloured Lighting System Design with Fuzzy Logic Controller
}

\author{
Paul W. Mutua*1, Mwangi Mbuthia ${ }^{2}$ \\ ${ }^{1}$ Department of Technical Services, Kenya Electricity Generating Compant Ltd. (KenGen) \\ Stima Plaza Phase II, Koloboti Road, Parklands, P.O.Box 47936-00100, Nairobi, Kenya \\ ${ }^{2}$ Department of Electrical and Information Engineering, University of Nairobi, Kenya \\ *Corresponding author, e-mail: pwmutua@yahoo.com
}

\begin{abstract}
This paper describes the design of an intelligent energy efficient lighting system that uses multi-coloured LEDs and a fuzzy logic controller to produce light of the required luminance level and colour in a typical room space. The lighting system incorporates automatic control of a room's window shade opening, conveniently harvesting daylight. Appropriate room occupancy sensors were set to dim off the LEDs if there are no people in the room. A movement sensor was also considered for dimming the LEDs if the persons in the room are asleep. A colour decoder was included in the control system, to determine the LEDs' output light colour and dim them off if the colour requirement is not selected. The colour decoder also closes the window shade if required light colour is not white. Two Fuzzy Logic controllers were used in the system; one to control opening of the room's window shade via microcontroller, and the other to control the LEDs' output luminance. The study was limited to simulation of the design in a MATLAB software environment using Fuzzy Logic Toolbox and Simulink blocks. The simulation test results confirmed that the LEDs' output luminance decreases as the amount of daylight entering the room increases. The designed system intelligently saves lighting electrical energy while maintaining the room's comfortable illumination levels and colour requirements.
\end{abstract}

Keywords: Fuzzy logic controller, Membership function, Artificial Intelligence, RGB LED lighting control, Daylight harvesting

Copyright (C) 2016 APTIKOM - All rights reserved.

\section{Introduction}

Nowadays lighting is seen also as a way of creating a pleasant atmosphere in the interior as a whole and as a means of providing comfortable conditions in which to live and work [4]. Since the discovery and use of incandescent electric lamps by end of 19th century, lighting systems have undergone many major developments. Research for more efficient lighting system is an on-going exercise driven by the need to create suitable illumination and colour for different occasions and enjoyment, and to save energy to meet the international requirements to reduce greenhouse gases. Lighting can account for up to $20 \%$ of a household's yearly electricity usage, and up to $40 \%$ a year in commercial buildings [4], [5].

The current generations of light emitting diodes (LEDs) are more efficient, some having efficacies of more than $100 \mathrm{~lm} / \mathrm{w}$ [7], [9], [10], [13]. The LED characterized by mercury-free, high efficiency, and long life cycle is expected to be the new generation light source [1], [13]. The use of control technology in electric light dimming, daylight harvesting, and movement detection can greatly improve lighting energy efficiency [5], [9], [10]. The new generation of multi-colour Red, Green, Blue LEDs (RGB LEDs) offer not merely another means to form white light but a new means to form light of different colours. As more effort is devoted to investigating this method, multi-colour LEDs should have profound influence on the fundamental method that we use to produce and control light colour [6-8], [14].

Most past papers on control of lighting in a room using Fuzzy logic controllers, deal with switching on or off number of lighting lamps [1], [11], [13]. Other papers are on dimming incandescent lamps [2] and controlling homogeneity of light intensity from LED lamps [12]. Other papers have shown use of Fuzzy logic controllers in daylight harvesting [8]. There is very little literature for design research on control of multi-coloured LED lighting using Fuzzy logic. Manually, on/off switching and discrete level dimmers can be used to control the amount of light provided in a space, however, there is not much timing accuracy using this technique-and people also forget. The main objective of this study was to 
design an intelligent lighting system based on fuzzy logic controller that uses multi-colour LEDs to produce light of the required luminance level and appropriate colour in a room space considering energy efficiency requirements. The study combines the benefits of daylight harvesting techniques and the exciting dynamics of coloured light from the modern RGB LEDs.

The comfortable brightness level in a room is a range which could conveniently be controlled using fuzzy logic controllers. The basic concept underlying fuzzy logic is that of a linguistic variable, that is, a variable whose values are words, such as large, small, very bright, etc, rather than numbers. Fuzzy logic uses fuzzy sets to relate classes of objects with unclearly defined boundaries in which membership is a matter of degree. Fuzzy logic is a very powerful tool for dealing quickly and efficiently with imprecision and non-linearity issues requiring decision making. Fuzzy system has ability to be built on top of the experience of experts and can be blended with conventional control technologies. The study was limited to simulation of the lighting system using Simulink blocks in MATLAB environment. However, a physical implementation scheme for the lighting system, using appropriate microcontrollers and addressable digital sensors, was also researched and proposed for future work.

\section{Research Method}

\subsection{Production of Coloured LED Light}

Additive mixing of Red, Green and Blue light colours will produce all other light colours, including white. If the three, red green and blue LEDs, are placed close to each other such that their combined output light fall on same surface, then the effective required light colour could be realized by varying the luminance level of each respective LED. Figure 1 is an illustration diagram showing how coloured light is produced by varying the respective LED current pulses.

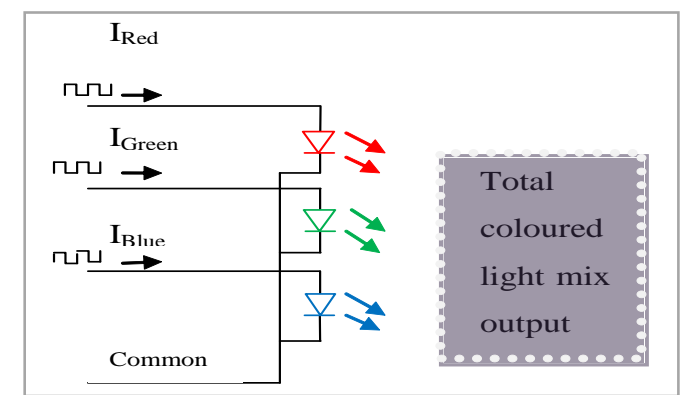

Figure 1. Illustration diagram for RGB LED colour mixing

The brightness of an LED is approximately proportional to its average current. However, a current variation in an LED may cause colour shift. Such an approach is not appropriate for applications, which strictly requires a consistent colour gamut (scale) [3]. For this reason a driver circuit is designed essentially to drive LEDs at the required constant current. This is best carried out using low frequency constant amplitude current pulses. Figure 2 is a circuit diagram demonstrating a LED's current pulse controlled driver. A "on/off switching" of the LED current circuit is controlled by the PWM pulse generator output signal. Figure 3 is the theoretical waveform of the PWM generator output signal, the voltage $\left(V_{R}\right)$ across the LED, and its current $\left(V_{R} / R\right)$.

A chopped dc voltage is produced in the LED resistor terminal:

$$
\mathrm{V}_{\mathrm{R}}=\mathrm{T}_{\mathrm{ON}} /\left(\mathrm{T}_{\mathrm{ON}}+\mathrm{T}_{\mathrm{OFF}}\right) \mathrm{V}_{\mathrm{s}}=\mathrm{T}_{\mathrm{ON}} / \mathrm{T} \mathrm{V}_{\mathrm{s}}=\alpha \mathrm{V}_{\mathrm{s}}
$$

Where: $\mathrm{T}=\mathrm{T}_{\mathrm{ON}}+\mathrm{T}_{\mathrm{OFF}}=$ chopping period.

$$
\alpha=\mathrm{T}_{\mathrm{ON}} / \mathrm{T}=\text { duty cycle (duty ratio) }
$$

RMS value of output voltage

$$
\mathrm{V}_{\mathrm{or}}=\left[\alpha \mathrm{V}_{\mathrm{s}}^{2}\right]^{1 / 2=} \sqrt{ } \alpha \mathrm{V}_{\mathrm{s}}
$$

RMS value of output current 


$$
\mathrm{I}_{\mathrm{or}=}\left[\alpha\left(\mathrm{V}_{\mathrm{s}} / \mathrm{R}\right)^{2}\right]^{1 / 2}=\sqrt{ } \alpha\left(\mathrm{V}_{\mathrm{s}} / \mathrm{R}\right)
$$

Power delivered to the LED

$$
\mathrm{P}_{\mathrm{LED}}=\mathrm{I}_{\mathrm{or}} \mathrm{V}_{\mathrm{or}}=\sqrt{ } \alpha\left(\mathrm{V}_{\mathrm{s}} / \mathrm{R}\right) \sqrt{ }_{\alpha} \mathrm{V}_{\mathrm{s}}=\alpha\left(\mathrm{V}_{\mathrm{s}}^{2} / \mathrm{R}\right)
$$

Hence, $\mathrm{P}_{\mathrm{LED}}=\mathrm{K} \alpha$

Where $\mathrm{K}$ is a constant, $\left(\mathrm{V}_{\mathrm{s}}^{2} / \mathrm{R}\right)$, as long as the dc source, $\mathrm{V}_{\mathrm{s}}$, is maintained constant.

The average LED current (average power) is controlled by varying the duty cycle $(\alpha)$ of the PWM pulse generator.

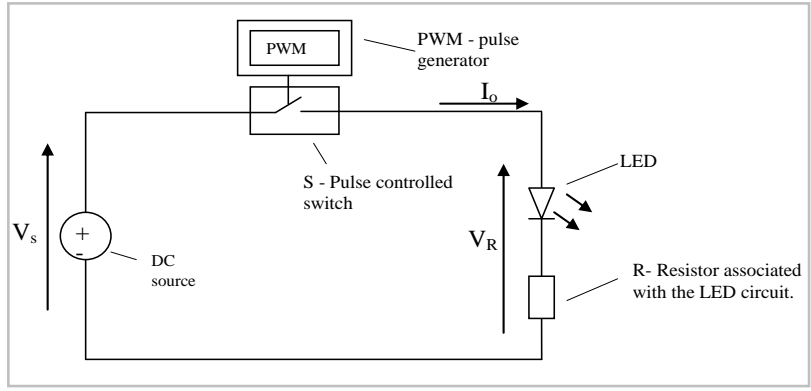

Figure 2. Circuit diagram PWM controlled LED driver

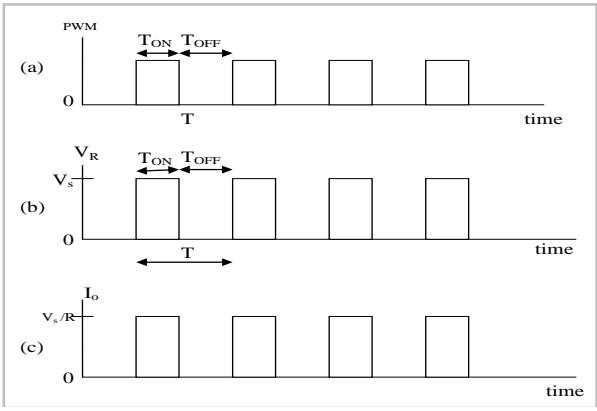

Figure 3. Theoretical waveforms for the driver pulses

\subsection{Existing Methods of Controlling RGB Leds' Light Colour}

A pulse duty cycle $(\alpha)$ is controlled by varying amplitude level of the generator's input reference signal. Most PWM generators required an input reference signal whose value level could be controlled in the range of 0 to 1 . There are three main methods for controlling duty cycle for each respective RGB LED driver to effect appropriate output light colour:

\subsubsection{Time Based Discrete Reference Input Signal Value Levels-Time Programmed Operation}

The controlling reference input signal value for each respective RGB pulse generator is constant for a set period of time after which it changes to another value level.

\subsubsection{Manually Set Discrete Reference Input Signal Value Levels-Manual Operation}

The controlling reference input signal value for each respective RGB pulse generator is constant and it remains so until a manual intervention is introduced and moves the signal value to another level.

\subsubsection{Continuously Varying Reference Input Signal Value Levels-Environmental Sensor Operated}

The controlling reference input signal value for each respective RGB pulse generator is not constant but keeps on varying in response to another signal from an appropriate environmental sensor. The operating signal is not timed nor manually manipulated.

The environmental sensor operated control signal method was chosen because of its ability to automate dimming of the RGB LEDs output light and vary its colour accordingly without human intervention. This method of automatic signal control is most suitable for Fuzzy Logic controllers.

\subsection{Fuzzy Logic Controllers}

Fuzzy logic controllers are fashionable in areas of artificial intelligence like in sense and control of intelligent systems. The controllers rely on expertise knowledge and desires of the system user. Very little programming is required. It is easier to program the controller using the already packaged software, Fuzzy Logic Toolbox, in MATLAB software environment. Fuzzy Logic control system was chosen as the most appropriate controller for the lighting system because of its generalization of light level settings, simplicity and auto-control. A basic configuration of a two input fuzzy logic controller is illustrated in Figure 4. The $U_{1}$ and $U_{2}$ in the diagram represent the first and the second input signals respectively. The output signal of the controller is a crisp value that may be used as reference for a PWM pulse generator. 


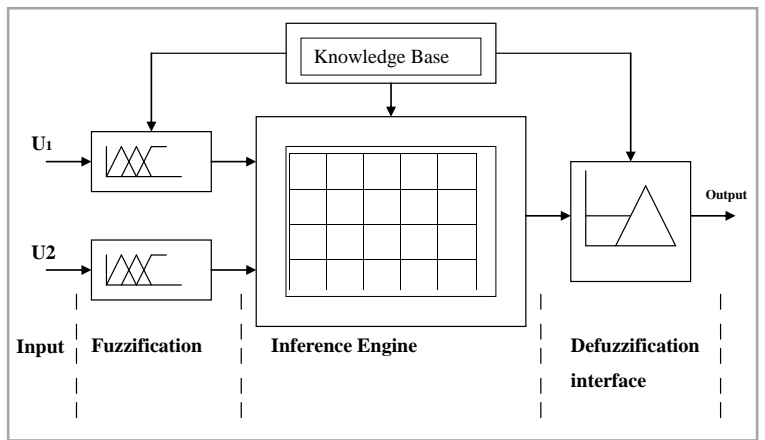

Figure 4. Illustration diagram for Fuzzy Logic controller

The fuzzy logic controller comprises of four principal components:

a. Fuzzification Interface:- It converts input into suitable linguistic values using a membership function.

b. Knowledge base:- Consists of a database with the necessary linguistic definitions and the control rule set.

c. Inference Engine:- It simulates a human decision making process in order to infer the fuzzy control action from the knowledge of the control rules.

d. Defuzzificztion interface:- Converts an inferred fuzzy controller output, using a membership function, into non-fuzzy (definite or crisp) control action signal.

The operation of the fuzzy logic controller is based on a set decision making control rules, fuzzy "IFTHEN" rules, of the form

$$
\mathrm{R}^{\mathrm{k}} \text { : IF } \mathrm{x}_{1} \text { is } \mathrm{F}_{1}{ }^{\mathrm{k}} \text { and } \mathrm{x}_{2} \text { is } \mathrm{F}_{2}{ }^{\mathrm{k}} \text { THEN } \mathrm{y} \text { is } \mathrm{G}_{\mathrm{k}}
$$

For $\mathrm{k}=1,2,3 \ldots \mathrm{n}$.

Where: $\mathrm{R}^{\mathrm{k}}$ is the $\mathrm{k}^{\text {th }}$ rule;

$\mathrm{x}_{1}, \mathrm{x}_{2}$ are members of $\mathrm{U}$, for example, and $\mathrm{y}$ is member of $\mathrm{V}$, and are the input and output of the fuzzy logic system, respectively;

$\mathrm{F}_{1}{ }^{\mathrm{k}}, \mathrm{F}_{2}{ }^{\mathrm{k}}$ and $\mathrm{G}_{\mathrm{k}}$ are labels of fuzzy sets in $\mathrm{U}_{1}, \mathrm{U}_{2}$ and $\mathrm{V}$ representing the $\mathrm{k}^{\text {th }}$ antecedent pairs and consequent pair respectively;

$\mathrm{n}$ is the number of rules.

\subsection{Typical Room Space and Lighting Control Design}

The Figure 5 is a labeled diagram representing a typical room whose inside illumination level is controlled by light from a set of ceiling mounted multi-colour LED lamps and outdoor daylight through clear-glass window with electrically movable shades (light blinders). It is assumed that the number and the rating of the multi-colour LED lamps is enough to illuminate the whole room uniformly and to the required light intensity. It is also assumed that the windows are large enough to allow passage of the daylight to illuminate the room uniformly to the required light intensity. The window shades are expected to blind out the outdoor light when in closed position. The amount of outdoor light entering the room is expected to be proportional to the opening of the window shades. Opening of the window shades is electrically controlled.

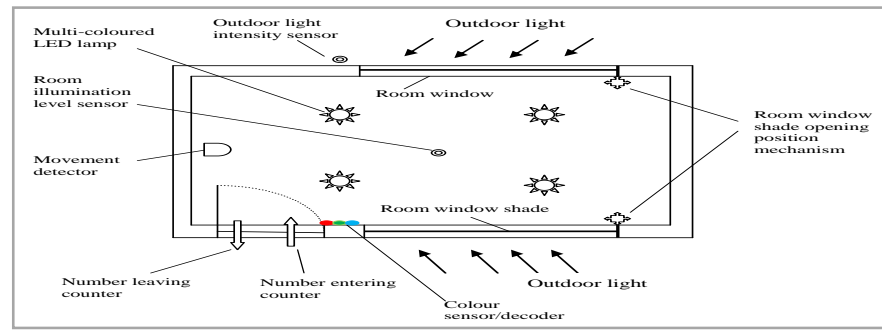

Figure 5. Typical room diagram with controlled light 
Figure 6 shows basic scheme of the multi-coloured lighting system with two fuzzy logic controllers; one for controlling position of the window light-shade opening and the other for controlling the LEDs' average output light intensity.

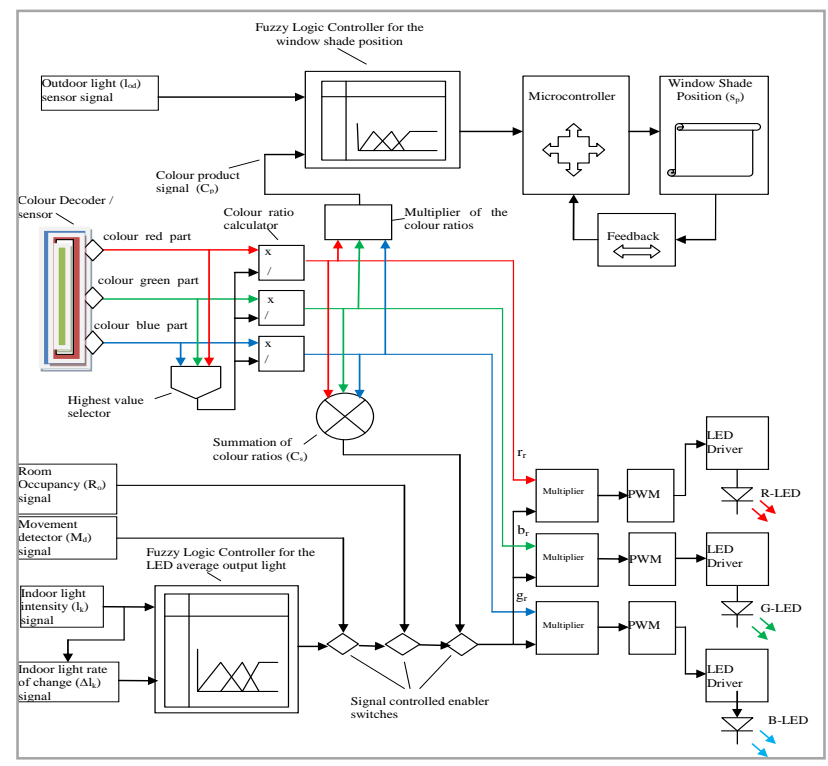

Figure 6. Basic scheme for the room lighting control

\subsection{The Window Shade Position Fuzzy Logic Controller}

The two inputs to the window shade opening position fuzzy logic controller are:

a. Outdoor light intensity level signal $\left(\mathrm{L}_{\mathrm{od}}\right)$

b. Colour ratio product signal (Cp)-the LEDs' output light colour is either 'white' or 'not white'

The selected Fuzzy Logic Inference system is Mamdani [Ref.], where the output is a crisp single number based on the centroid moment of the aggregated output membership function. Figure 7 shows the required membership function (fuzzy logic graph) for fuzzification of the input $1_{\text {od, }}$ outdoor light level. The input range was on scale of 0 to 10 for convenience in the test.

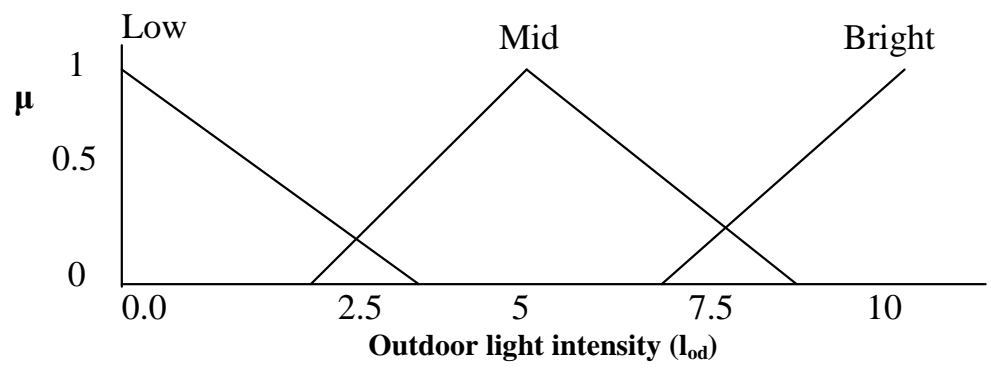

Figure 7. Outdoor light level input-Membership function

Figure 8 shows the required membership function (algorithm plot) for the input colour ratio product signal $\mathrm{C}_{\mathrm{p}}$. The Universe of Discourse, which is the $\mathrm{x}$-axis, range from 0 signal value to 1 signal value, convenient for the light colour ratio product range. For convenience the, light colour was considered white if the colour parts ratio product is between 0.85 and 1 . 


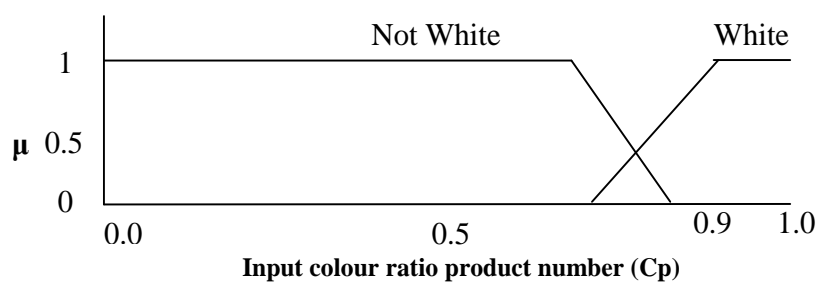

Figure 8. Colour ratio product signal-Membership function

Figure 9 shows the window shade position fuzzy logic controller output membership function algorithm plot for defuzzification of the output, $\mathrm{P}_{\mathrm{r}}$, The output position reference scale is 0 to 1 , with 0 standing for fully closed and 1 for fully open window shade position.

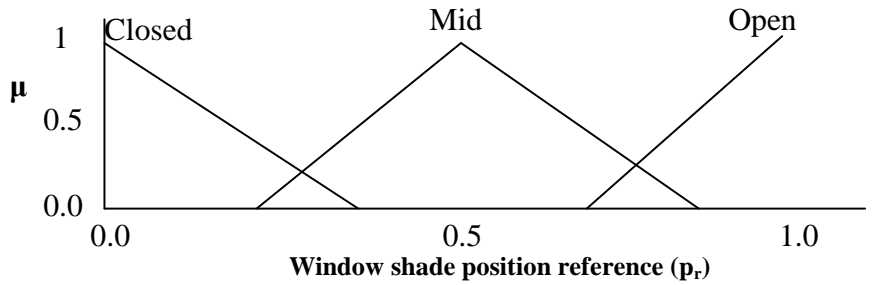

Figure 9. Window shade position output-Membership function

Table 1. Fuzzy control rules for inputs outdoor light level $\left(l_{\text {od }}\right)$ and colour ratio product signal $\left(\mathrm{c}_{\mathrm{p}}\right)$.

\begin{tabular}{llll}
\hline Outdoor light $\left(\mathrm{l}_{\mathrm{od}}\right)$ Colour product $\left(\mathrm{c}_{\mathrm{p}}\right)$ & Low & Mid & High \\
\hline White & Closed & Open & Mid \\
Not White & Closed & Closed & Closed \\
\hline
\end{tabular}

\subsection{The LEDs' Output Fuzzy Logic Controller}

Figure 10 is the membership function algorithm plot for the room light intensity level where the input Universe of Discourse ranges from 0 to 10. Figure 11 is the membership function algorithm plot for the rate of change of the input indoor light intensity. The Universe of Discourse ranges from -1 to 1.

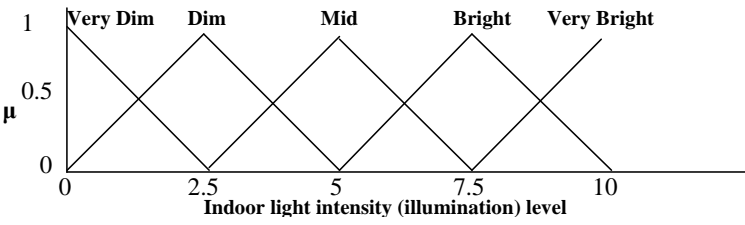

Figure 10. Indoor light intensity-input membership function

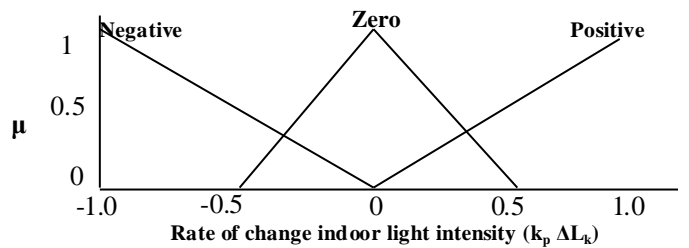

Figure 11. Rate of change of Indoor light intensity-membership function

Figure 12 is the membership function algorithm plot for output of the LEDs' output light level fuzzy logic controller. The Universe of Discourse range from 0 to 2 for convenience of computing the respective LED's colour ratio signal level. 


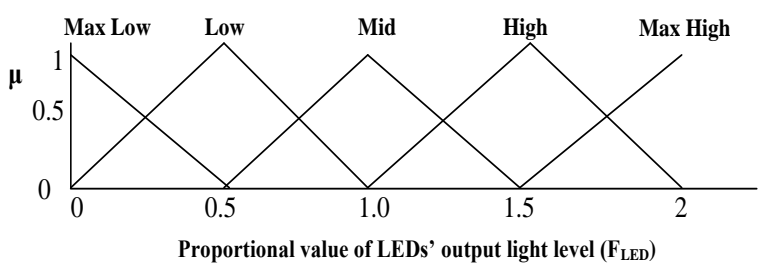

Figure 12 LEDs' output light intensity-output membership function

Table 2 shows a matrix of rules for controlling the LEDs average power output using the indoor light level $\mathrm{L}_{\mathrm{k}}$ and its rate of change $\Delta \mathrm{L}_{\mathrm{k}}$.

Table 2. LEDs output fuzzy control rules

\begin{tabular}{llll}
\hline Rate of change Room light & Negative & Zero & Positive \\
\hline Very Dim & Max High & Max High & High \\
Dim & Max High & High & Mid \\
Mid & High & Mid & Low \\
Bright & Mid & Low & Max Low \\
Very Bright & Low & Max Low & Max Low \\
\hline
\end{tabular}

\subsection{Simulation Scheme}

The lighting system software model was assembled and tested using the Simulink blocks in a MATLAB-Simulink environment. Algorithms for the fuzzy logic controllers were in form of membership function plots and control rules configured using the Fuzzy Logic Toolbox. Figure 13 is a screenshot showing the fully blocks-assembled simulation model on Simulink platform.

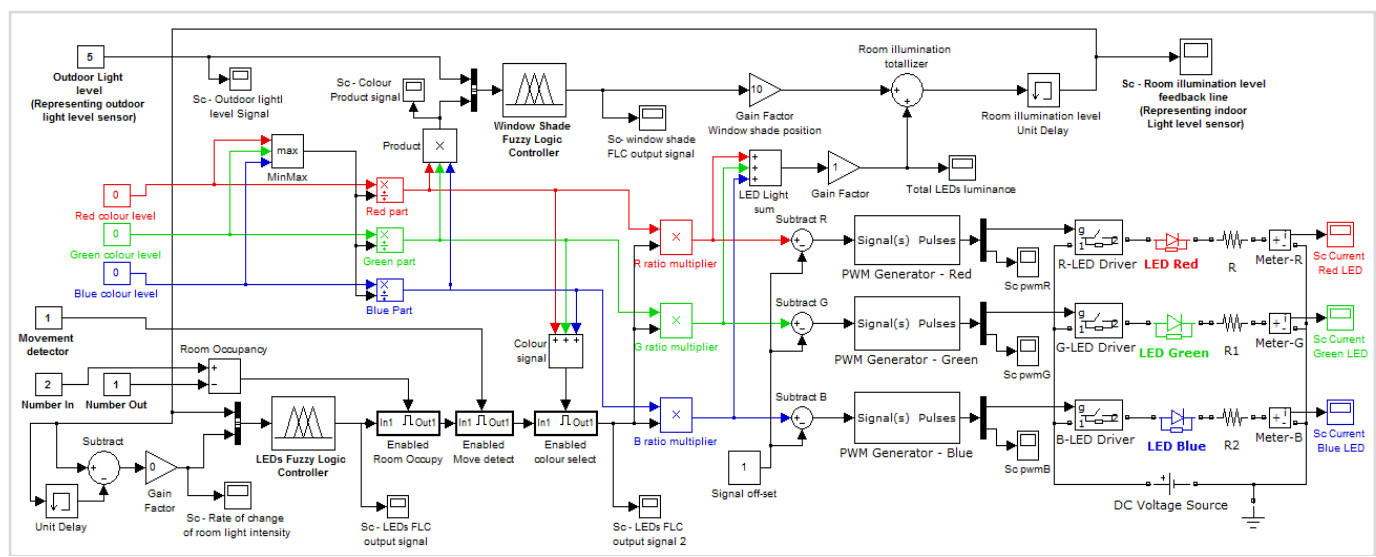

Figure 13. Screen shot of the blocks-assembled simulation model on Simulink platform

The simulation was based on assumption that the daylight contribution to the indoor light (illumination) is directly proportional to the window shade opening position. That is, the outdoor light to the room $\left(\mathrm{L}_{\mathrm{od}}\right)$ is equal to constant $\left(\mathrm{k}_{\mathrm{od}}\right)$ times the window shade position control signal $\left(\mathrm{p}_{\mathrm{r}}\right)$, as equation (6)

$$
\mathrm{L}_{\mathrm{od}}=\mathrm{k}_{\mathrm{od}} \mathrm{p}_{\mathrm{r}}
$$

The LEDs' light output $\left(\mathrm{L}_{\mathrm{LED}}\right)$ is equal to constant $\left(\mathrm{k}_{\mathrm{LED}}\right)$ multiplied by sum total of the signals input to the PWM generators $\left(\mathrm{S}_{\mathrm{pwm}}\right)$ as shown by equation (7). 
$\mathrm{L}_{\mathrm{LED}}=\mathrm{k}_{\mathrm{LED}} \mathrm{S}_{\mathrm{pwm}}$

The room illumination level $\left(\mathrm{R}_{\mathrm{i}}\right)$ is equal to sum of both outdoor light and the LEDs output as shown in equation (8).

$$
\mathrm{R}_{\mathrm{i}}=\mathrm{k}_{\mathrm{od}} \mathrm{p}_{\mathrm{r}}+\mathrm{k}_{\mathrm{LED}} \mathrm{S}_{\mathrm{pwm}}
$$

Indoor light signal feedback to the LEDs fuzzy logic controller $\left(\mathrm{L}_{\mathrm{k}}\right)$ is shown in equation (9), where $\mathrm{z}^{-1}$ is unit delay in sampling.

$$
\mathrm{L}_{\mathrm{k}}=\mathrm{z}^{-1} \mathrm{R}_{\mathrm{i}}=\mathrm{R}_{\mathrm{i}-1}
$$

Rate of change of indoor light $\left(\Delta \mathrm{L}_{\mathrm{k}}\right)$ is equal to room light intensity signal value $\left(\mathrm{R}_{\mathrm{i}-1}\right)$ minus one simulation time delayed room light intensity value $\left(\mathrm{R}_{\mathrm{i}-2}\right)$, as shown in equation (10).

$$
\Delta \mathrm{L}_{\mathrm{k}=} \mathrm{R}_{\mathrm{i}-1}-\mathrm{R}_{\mathrm{i}-2}
$$

In the simulation, outdoor light signal was manually input. A preset sinusoidal signal generator was also used in testing effect of varying the outdoor light levels. The colour decoder, in the simulation block, is represented by three constant blocks; one for level value of colour red, another for level value of colour green, and the other level value of colour blue. Each colour portion level value constant was input manually. Both the movement detector and the room occupancy signals were also manually input. Signal level for each part on the model was monitored by means of connected Simulink scope blocks.

\subsection{Physical Implementation schematic diagram}

Figure 14 shows a schematic diagram with actual industrial electronic devices proposed for implementing the RGB LED room lighting system. The electronic/digital devices are expected to intercommunicate through $\mathrm{I}^{2} \mathrm{C}$ bus or any other appropriate digital communication protocol. The software for the Fuzzy Logic Controllers and signal flow programming would be installed in the master microcontroller.

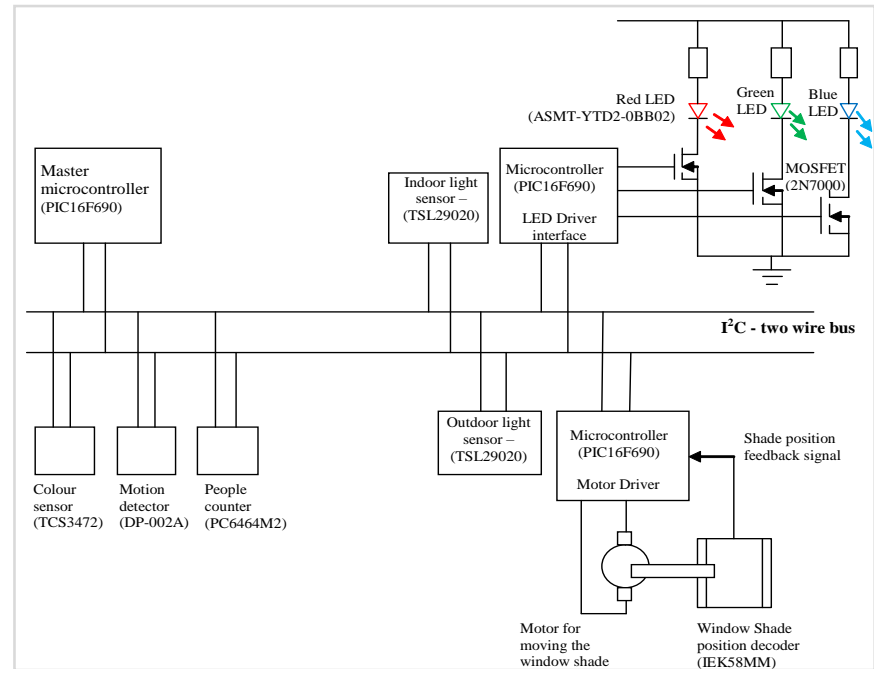

Figure 14. Schematic diagram for implementation

\section{Results and Analysis}

Inputs to the simulation model were in form of constant values based on Simulink constant blocks specific for outdoor light intensity, red colour, green colour, blue colour, movement detector, number entering room, and number leaving room respectively. Also used as input is a sinusoidal signal generator for the outdoor light sensor. 
The simulation model outputs were monitored using the Simulink scope blocks each for window shade position controller output, the indoor light intensity level feedback, the rate of change of the indoor light intensity, the LEDs fuzzy logic controller output, the light colour ratio product, and the LEDs' currents respectively. Throughout the experiment, the simulation time was set at 0.005 seconds.

\subsection{Effect of outdoor light intensity on indoor illumination levels and the LEDs' output.}

The objective of this simulation was to check how various values of the outdoor light intensity affect the model's window shade position fuzzy logic controller output signal, the overall indoor illumination levels, and the LEDs fuzzy logic controller output signals. In this test, the outputs of the window shade position fuzzy logic controller were expected to follow the control if-then rules as in Table 1. For outdoor light intensity values varying from zero to ten, the window shade position was expected to be at closed position of values (about $0-3$ ), then start opening to maximum values (about $0.8-1$ ), the partially close to values (about $0.6-0.4$ ). The test results are shown in Figure 15 which is a line graph where the values of the outdoor light intensity are compared with the resulting values of the window shade position controller output, the indoor illumination levels, and the LEDs' fuzzy logic controller output.

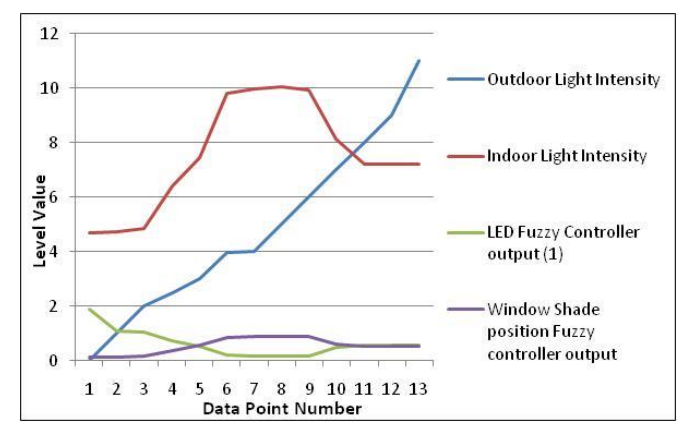

Figure 15. Line graph for effect of outdoor light intensity

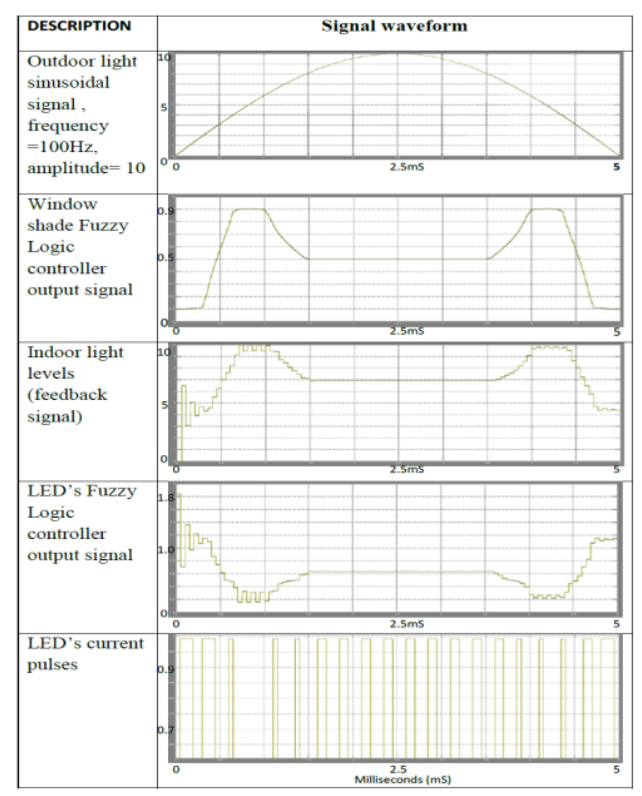

Figure 16. Signal waveforms as effect of outdoor light 
A signal generator with sinusoidal output was also used for the outdoor light intensity. The resulting waveforms of the window shade controller output, the indoor illumination level, and the LEDs' controller output signals are tabulated in Figure 16.

The line graphs in Figure 15 and the waveforms in Figure 16 show that the indoor illumination level values increase with increase of the outdoor light intensity but following thewindow shade opening position fuzzy logic controller statement rules in Table 1 . At very low outdoor light intensity levels, less than value 2 , the window shade opening signal is very low, about 0.18 . At middle levels of the outdoor light intensity, about 4 to 6 values, the window shade opening signal is at maximum, about 0.9. At high levels of the outdoor light intensity, about 8 to 10 values, the window shade opening signal is at middle position, about 0.7 .

It was also noted that at very low outdoor light intensity levels, less than value 2 , the indoor illumination level values are lowest but the LEDs' fuzzy logic controller output signal is at highest, just as per the LEDs output fuzzy logic controller control rules in Table 2. The oscillation in the indoor light intensity wave forms were noted and expected to be caused by the LEDs' controller trying to compensate for the varying indoor illumination levels. At middle levels of the outdoor light intensity, the indoor illumination level is highest, about 10, while the LEDs' controller output is lowest, at about 0.16. At high levels of the outdoor light intensity the indoor illumination level values are at middle as well as the LEDs' controller output. The objective of this test for checking how various values of the outdoor light intensity affect the model's functions was successful. The window shade position fuzzy logic controller output signal behaved as expected. Graph 3.1 shows that window controller output signal smoothly rise from low values to high values, then lowers to mid values. It was also noted that there three flat sections; the window shade closed position (0.18), the fully open position (0.9), and the mid open position (0.7). This confirmed that the window shade position fuzzy logic controller was operating in response to the control "if-then" rules set out in Table 1.

The LEDs fuzzy logic controller output signal was also noted to follow the indoor illumination level but in contrasting manner. As the indoor light intensity increases, the LEDs controller signal decreases. The indoor light intensity signal was noted to oscillate at particular outdoor light signal levels. This is lighting behavior was as expected.

The outdoor light intensity level automatically, but through the window shade opening, determines the output signal level of the LEDs' fuzzy logic controller. The more the window shade is opened, the lower the average power used by the LEDs. Figure 16 confirms that LED's current pulses are narrower where the window shade opening is high. Width of the pulses is directly proportional to the duty cycle $(\alpha)$ of the PWM pulse generator which is also proportional to the controller's output signal level. The pulse period is constant at $0.25 \mathrm{~ms}$.

The test also confirmed that the current pulse width for the controlled LEDs lighting was increasing with the LEDs fuzzy logic controller output signal and vice-versa. This is as was expected and confirms that the design model was functional and effective in saving electric energy for lighting a typical room when the outdoor daylight is available. The fuzzy logic controllers do not provide the expected absolute lowest set signal values, as 0 , or the highest set values. This problem was noted as weakness with fuzzy logic controllers. The inaccuracy could be improved by increasing the number of "if-then" rules and narrowing the respective membership function plots.

\subsection{Effect of Different Level Values of the Red, Green and Blue Colour Portions}

The objective of this simulation was to confirm the model's ability to calculate ratio values of the primary colours (red, green, and blue), reproduce a signal that represents the whiteness of the selected colour (colour ratio product) which is used as an input to the window shade position fuzzy logic controller. It was expected that for white light signal, the product of the colourratios would be close to value of 1 . Coloured light signal were expected to have colour ratio product of less than 0.8 . The other objective of this test was to confirm if the system model could use the primary colour ratios to determine the respective RGB LEDs current pulse width. It was expected that for smaller colour ratio, the respective colour LED current pulse width would also be narrower. The highest colour ratio value was expected to be 1 and the respective colour LED current pulse width would be widest and in proportion to the controlling signal value from the LEDs fuzzy logic controller. The colour ratio product was also expected to close the window shade if its signal value is less than 0.8. Contribution of the LEDs light to the indoor illumination level was expected to be proportional to the colour ratio product.

Figure 17 is a line graph showing the various signal values of the red, green and blue colour portions and their ratio product, Figure 18 is a line graph showing the relationship of the colour ratio 
product signal, the window shade fuzzy logic controller output, and the LEDs' fuzzy logic controller output signals.

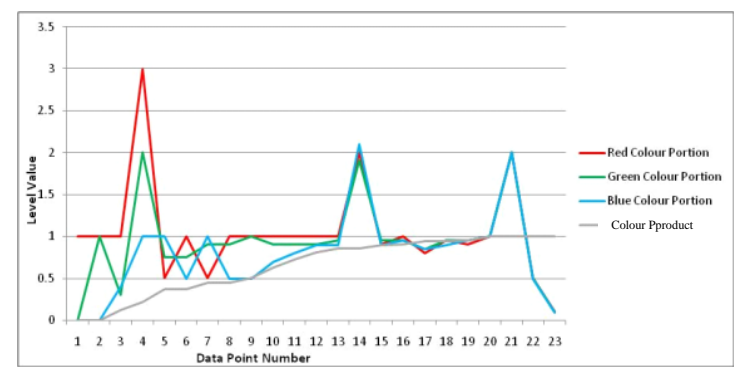

Figure 17. Line graphs on effect of colour level values.

The line graph shows that when the red, green, and blue colour portion level values are not close to each other, their ratio product tends to zero, but if close their ratio product signal value tends to 1 .

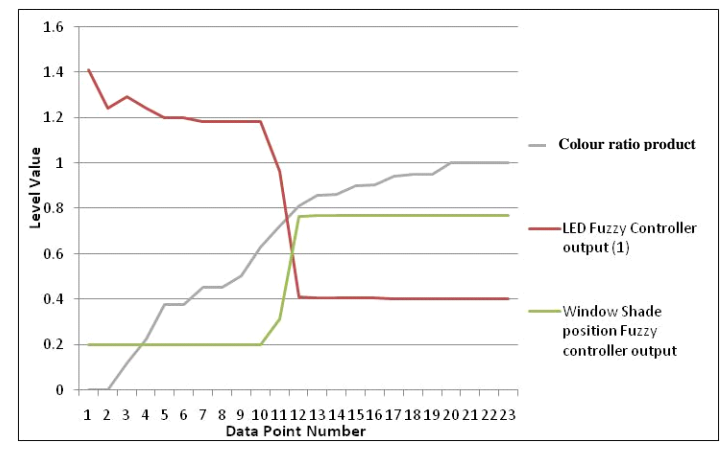

Figure 18. Line graph on effect of the colour ratio product

The line graph shows that the window shade position fuzzy controller output is at lowest value, about 0.2 , when the colour ratio products are low, from 0 to about 0.6 . The window shade position fuzzy controller output is at and highest value, about 0.78 , when the colour ratio products are highest, from 0.8 to 1.This demonstrates that the lighting system model window shade opens only when the LEDs' output light colour is white.

Figure 19 is a set of screen shots showing signal waveforms for the indoor light levels, LEDs fuzzy controller output, red LED current pulses, green LED current pulses, and Blue current pulses.

The test confirmed that the model could calculate ratio values of the primary colours (red, green, and blue), and the colour ratio product used as an input to the window shade position fuzzy logic controller. The model would recognize white light and open the window shade for the daylight to shine in the room. White light signal was confirmed to have colour ratio product value of more than 0.8 . The test also confirmed that model design could use the primary colour ratios to determine the respective RGB LEDs current pulse width. The smaller the colour ratio, the narrower the respective colour LED current pulse width would be. The smaller the LEDs current pulse width, the less the intensity of light (luminance) from the respective LED. Hence the colour ratio signal value for each respective primary colours determine the overall colour of the combined light from the three RGB LEDs. Hence, the system design model demonstrated that it can effectively control colour of light produced by the LEDs in a typical room. 


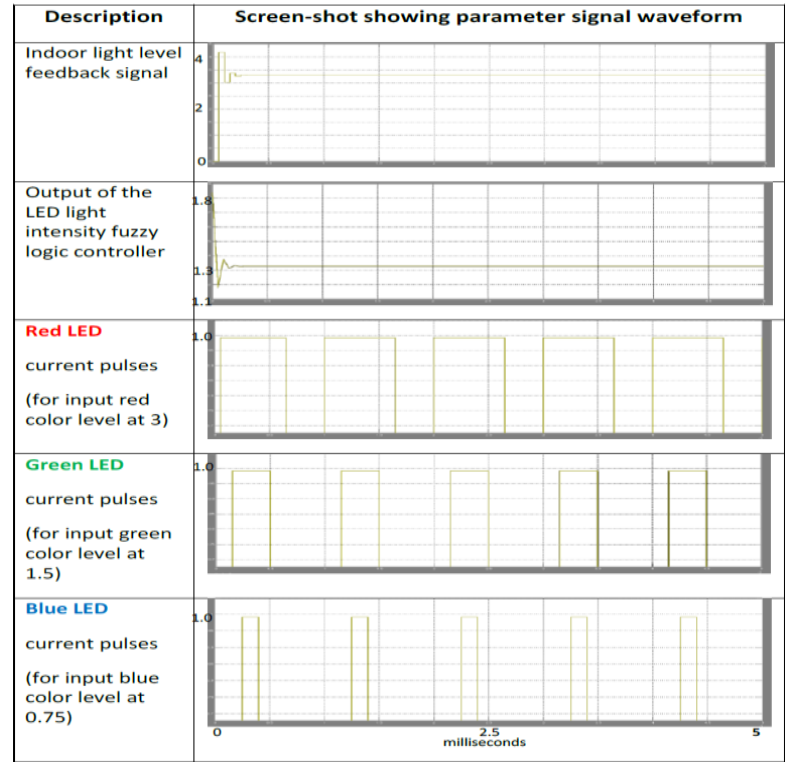

Figure 19. Set of screen shots showing the signal waveforms

\section{Conclusion}

The simulation model confirmed the objectives of the study. The simulation model demonstrated how a fuzzy logic controller can be used to process an outdoor light level signal in automatic control of a typical room's window shade position, and hence heuristically harvest daylight for energy efficient illumination of the room. The simulation model design also proved that an indoor light intensity level sensor signal could be processed through a fuzzy logic controller to intelligently control a room's LEDs light intensity and maintain the required illumination level. The simulation model design also demonstrated that the lighting system LEDs could be dimmed off by a signal from either the colour decoder, or the room occupancy counter or the movement detector. The model design demonstrated how an output of a colour sensor (colour decoder) with three distinct signal lines, each for each specific primary colours, could be processed accurately to determine a RGB LEDs' lamp output light colour. The system calculated the respective colour portion ratios then used it to apportion the average power for each respective red, green, and blue colour LED. The model simulated how the calculated colour portion ratios could be used to differentiate a white light from coloured one and then close the room's window shades if room required light is not white.

The integrated system of sensors, fuzzy logic controllers, and the multi-coloured LEDs is energy efficient and intelligent, ensuring that the electric energy for the LEDs is used only when the outdoor daylight is not enough and only when the room is occupied and the user is not asleep. The lighting system is sensitive to colour needs; the window shade closes when the room's required light colour is not white. However, the simulation results showed that the lowest level of the LEDs out is not zero as expected. This problem was associated with fuzzy logics' weakness of approximation. Lowest value of the fuzzy logic controller output is not zero but a number with approximate value of zero. The research work was limited to model simulation, and therefore, further research in implementing the system is recommended.

\section{Acknowledgements}

I would like to take this opportunity to thank my supervisor and co-auther, Eng.Prof. Mwangi Mbuthia, for his valuable guidance and support throughout my MSc. course and this research work.I take this early opportunity to thank the top management of KenGen, for allowing me to think freely on engineering academics and by extension sponsoring this research studies. I would also like to thank my postgraduate colleagues and all staff in the Department of Electrical and Information Engineering, University of Nairobi, for their support and encouragement. 


\section{References}

[1] D. Panjaitan and A. Hartoyo, A Lighting Control System in Buildings Based on Fuzzy Logic, Telkominka Vol 9 No. 3 Dec 2011 pp 423-432.

[2] M. L. Jin and M. C. Ho, Labview-Based Fuzzy Controller Design of a Lighting Control System, Journal of Marine Science and Technology Vol. 17, No. 2, pp. 116-121 (2009).

[3] C. S. Moo, Y. J. Chen and W. C. Yang, An Efficient Driver for Dimmable LED Lighting, IEEE Trans On Power Electronics, Vol 27, No.11, Nov. 2012.

[4] Philips Lighting Academy (notes), Basics of Light and Lighting, 2008 Koninklijke Philips Electronics N.V., Document order no. 322263558631 (2008).

[5] Lighting Design International Inc., Lighting Design, Available: http://www.crystalfoundains.com/need/ Accessed in December 2012.

[6] Y. Ohno, Colour Rendering and Luminous Efficacy of White LED Spectra, Fourth International Conference on Solid State Lighting (Proc. of SPIE), vol. 5530, pp.88-98 (2004).

[7] N. Zheludev, The Life and Times of LED- a 100 year history, Nature Publishing Group, April 2007, Available: www.nature.com/naturephotonics. Accessed in January 2013.

[8] M. T. Lah, B. Zuancic, J. Peternel, and A. Krainer, Daylight Illuminance Control with Fuzzy Logic, Solar Energy 80 (2006), Available: www.sciencedirect.com. Accessed in January 2013

[9] Simmtronic Lighting Control, SPECS3 Lighting Control System, Simmtronic Ltd, application manual, Available: www.simmtronic.com. Accessed in January 2013.

[10] Lutron Electronics co. Dimming Range Adjustment - Important Notes about your Dimmers, Lutron Electronic Co. Inc-Application notes, Sep 2012, Available: www.lutron.com/dimflled. Accessed in January 2013.

[11] C. Zhang, N. Cui, M. Zhong, and Z. Cheng, Application of Fuzzy Decision in Lighting Control of Cities 44th IEEE Conference on Decision and Control, and the European Control Conference 2005, pp 4100-4104, 0-78039568-9/05- ()2005 IEEE

[12] M.G. Shafer, E. Saputra, K.A.Bakar, F. Ramadhani, Modeling of Fuzzy Logic Control System for Controlling Homogeneity of Light Intensity from Light Emitting Diode, Intelligent Systems, Modelling and Simulation (ISMS), 2012 Third International Conference, pp 71-75.

[13] S. Mehan, Introduction of Traffic Light Controller with Fuzzy Control System, International Journal of Electronics and Communications Technology, vol. 2, issue 3, pp 119-122, Sep 2011. Available: www.Iject.org.

[14] R. Stevenson, "The LED Lighting: Blue+Yellow=White", Part of IEEE Spectrum's special report: Top 11 Technologies of the Decade, No.4, summary by Richard Stevenson, Available: http://spectrum.ieee.org/static/special-report-top-technologies-of-the-decate Accessed in August 2013 